\title{
The Culture, Sexual and Asexual Reproduction, and Growth of the Sea Anemone Nematostella vectensis
}

\author{
CADET HAND AND KEVIN R. UHLINGER \\ Bodega Marine Laboratory, P.O. Box 247, Bodega Bay, California 94923
}

\begin{abstract}
Nematostella vectensis, a widely distributed, burrowing sea anemone, was raised through successive sexual generations at room temperature in non-circulating seawater. It has separate sexes and also reproduces asexually by transverse fission. Cultures of animals were fed Artemia sp. nauplii every second day. Every eight days the culture water was changed, and the anemones were fed pieces of Mytilus spp. tissue. This led to regular spawning by both sexes at eight-day intervals. The cultures remained reproductive throughout the year. Upon spawning, adults release either eggs embedded in a gelatinous mucoid mass, or free-swimming sperm. In one experiment, 12 female isolated clonemates and 12 male isolated clonemates were maintained on the 8-day spawning schedule for almost 8 months. Of the female spawnings, $75 \%$ occurred on the day following mussel feeding and water change, and $64 \%$ of the male spawnings were similarly synchronized under this regime. Fertilization and development occur when gametes from both sexes are combined in vitro. At $20^{\circ} \mathrm{C}$, the embryos gastrulate within 12-15 hours. Spherical ciliated planulae emerge from egg masses $36-48$ hours post-fertilization. The planulae elongate and form the first mesenteric couple, as well as four tentacle buds, by day five. By day seven, they metamorphose and settle as $250-500 \mu \mathrm{m}$ long, four-tentacled juvenile anemones. More tentacles and all eight macrocnemes are present at 2-3 weeks. Individuals may become reproductively mature in as few as 69 days. Nematostella vectensis has the potential to become an important model for use in cnidarian developmental research.
\end{abstract}

\section{Introduction}

Many sea anemones can be maintained for long periods under a variety of conditions including non-circulating

Received 25 July 1991; accepted 13 January 1992. water at room temperatures (Stephenson, 1928), and under the latter conditions some species produce numerous asexual offspring by a variety of methods (Cary, 1911; Stephenson, 1929). More recently this trait has been used to produce clones of genetically identical individuals useful for experimentation; i.e., Haliplanella luciae (by Minasian and Mariscal, 1979), Aiptasia pulchella (by MullerParker, 1984), and Aiptasia pallida (by Clayton and Lasker, 1984). We now add one more species to this list, namely Nematostella vectensis Stephenson (1935), a small, burrowing athenarian sea anemone synonymous with $N$. pellucida Crowell (1946) (see Hand, 1957).

Nematostella vectensis is an estuarine, euryhaline member of the family Edwardsiidae and has been recorded in salinities of 8.96 to $51.54 \%$ and water temperatures of $-1^{\circ}$ to $28^{\circ} \mathrm{C}$ (Williams, 1983 ). It is a small animal, usually less than $2 \mathrm{~cm}$ long and a few millimeters in diameter when found in the field (Williams, 1983). It occurs in England, from Nova Scotia to Georgia on the North American Atlantic coast, from Florida to Louisiana along the shores of the Gulf of Mexico, and from California to Washington on the Pacific coast (Hand, unpub. Louisiana record; Heard, 1982; Kneib, 1985; Williams, 1983). Williams (1983) considered the species vulnerable to extinction in Great Britain, but it is plentifully abundant throughout most of its range and is readily collected. $\mathrm{Ne}$ matostella occurs in soft sediments, in plant debris, and among living plants in permanent pools and tidal creeks in salt marshes. It also occurs subtidally in estuaries in Chesapeake Bay (M. Posey, pers. comm.; Calder, 1972) and in the Indian River in Delaware (Jensen, 1974).

To date we have only the barest outline of the life history of this species. Crowell (1946) and Frank and Bleakney (1976) reported that eggs were discharged in mucoid masses accompanied by numerous nematosomes. Nematosomes, which occur in the coelenteron, are spherical, $15-45 \mu \mathrm{m}$, flagellated bodies containing nematocysts and 
are known only from the genus Nematostella (Williams, 1979). Frank and Bleakney (1976) reported that planula larvae developed from the eggs, but subsequently disappeared, and Williams (1975) found three, $1.0 \mathrm{~mm}$ long planulae that he attributed to Nematostella in a pool containing that sea anemone. Rudy and Rudy (1983) kept $N$. vectensis in the laboratory for five years and stated that eggs developed to planulae in three days and to "fourknobbed" juveniles, i.e., with four tentacle buds, in five days. The sexes are separate (Hand, 1957; Frank and Bleakney, 1976; Williams, 1975), and N. vectensis reproduces asexually by transverse fission (Lindsay, 1975; Williams, 1976; Frank and Bleakney, 1978).

Even less is known about the natural history of $N$. vectensis. Kneib (1985) has shown that the grass shrimp $\mathrm{Pa}$ laemonetes pugio may prey on this anemone, and Lindsay (1975) and Frank and Bleakney (1978) have given us information on the anemone's diet. We also know that it tolerates extremes of temperature and salinity (Bleakney and Meyer, 1979; Stephenson, 1935) and, at times, may occur in dense populations, i.e., over 5 million in a single pool (Williams, 1983) and 1816 in a $15 \mathrm{~cm}^{2}$ sample (Bleakney and Meyer, 1979). Little beyond this is known of its natural history.

Here we describe the culture, reproduction, development, and growth of Nematostella, as well as some other aspects of its biology. In particular, we show that this anemone reproduces sexually in standing water at room temperature, is readily raised through successive generations, is sexually active throughout the year, and shows no sign of seasonality in its reproduction in the laboratory. This combination of traits-namely asexual reproduction, which allows the development of clones, and sexual reproduction with subsequent development through larval stages to reproductive adults, all under room temperature culture conditions-suggests that this sea anemone should be useful in the study of cnidarian biology, particularly development.

\section{Materials and Methods}

In December 1987, we received 12 living $N$. vectensis that had been collected subtidally from the Rhode River, a subestuary of the Chesapeake Bay in Maryland. The largest of these anemones was about $15 \mathrm{~mm}$ long when fully extended. The salinity at the time and place of collection was about $12 \%$. These Rhode River anemones, together with their sexual and asexual descendants, have been maintained in our laboratory and now number several thousand. It is from these cultures that isolated female and male clonemates were reared (see below). We also have cultures of Nematostella from England, Nova Scotia, Georgia, California, Oregon, and Washington.

\section{Culture methods}

Our cultures were maintained in crystallizing dishes with plastic Petri dish parts as covers. They were kept at room temperatures ranging from $16-26^{\circ} \mathrm{C}$, and at a salinity of about $12 \%$. We did not provide these animals with any substrate, such as silt or fine sediments, nor did we provide aeration to the cultures. The water was changed weekly to bi-weekly, but solitary anemones or cultures of only a few individuals may actually be kept for several weeks in unchanged water. Nematostella will tolerate crowding. We have raised about 300 sea anemones to lengths of $2-4 \mathrm{~cm}$ in a single $80 \times 40 \mathrm{~mm}$ dish containing $100 \mathrm{ml}$ of water, and we have reared equal numbers from planulae to young sea anemones, about $1.0 \mathrm{~cm}$ long, in $25 \mathrm{ml}$ of water in $51 \times 31 \mathrm{~mm}$ dishes.

We fed Artemia nauplii to our cultures every second day, and cultures have been maintained for more than two years on that diet alone; we have used both San Francisco Bay Brand and Sanders Premium Great Salt Lake Artemia. Other foods used were the yolk of hard boiled hens' eggs and veliger larvae of mussels and oysters. These are readily accepted by recently metamorphosed sea anemones. Tissues from Mytilus edulis and M. californianus, such as the ovary cut into $1-2 \mathrm{~mm}$ pieces, are also readily eaten by larger Nematostella.

\section{The production of isolated female and male clonemates}

The 12 Nematostella received from the Rhode River in December 1987 grew rapidly and began producing fertile egg masses in February 1988. From these and subsequent spawnings we reared several hundred Nematostella to sexual maturity. To observe spawnings more closely and to control the time of fertilization, we isolated sibling anemones that were several months old. By April 1989 we had isolated 16 mature and reproductively active females and 14 reproductive males. Each animal was held in a $51 \times 31 \mathrm{~mm}$ dish containing $25 \mathrm{ml}$ of $33 \%$ seawater, and each was fed 3-5 drops of concentrated Artemia nauplii every second day. Each animal was fed small pieces of $M$. californianus ovary every eighth day, the water in each dish was changed irregularly, and the pattern of spawning was observed.

In time, through asexual reproduction by transverse fission, many of the isolated individuals became clonal groups, and in the period from February 1989 to December 1989 , one particular isolated male anemone became a clone of 96 individuals and one female became a clone of 38 . From these two clones, we isolated 12 female and 12 male clonemates as above. These isolated anemones were fed several drops of nauplii every second day and two pieces of $M$. californianus ovary every eighth day followed by a water change. We recorded spawnings for these anemones from 12 February to 3 October 1990 (Table I). 


\section{Effects of salinity}

Because Nematostella is euryhaline and because it reproduced frequently for us, we explored the effect of salinity on both sexual and asexual reproduction. We prepared the following concentrations of seawater: $10 \%, 20 \%$, $33 \%, 66 \%, 100 \%, 125 \%$. The salinity of the $100 \%$ seawater was $34 \%$, and the $125 \%$ seawater was prepared by evaporation. We selected 6 groups of 20 anemones each from a culture of about 300 , essentially mature, 6-month-old siblings, $2.0-3.0 \mathrm{~cm}$ long. Other than the group of 20 that was to stay in $33 \%$ seawater, each group was acclimated to the desired final concentration by being successively moved, every four days, through the increasing or decreasing concentrations. We fed these anemones brine shrimp nauplii every second day, and recorded their sexual and asexual reproduction for a sixteen week period, from mid-October 1988, to the end of January 1989.

\section{Results}

\section{Sexual reproduction}

In our cultures, anemones become sexually mature at three to four months of age and at column lengths of between 1.5 and $3.5 \mathrm{~cm}$. The sexes are separate, and individuals that have been isolated for more than two years continue on as either males or females. We have seen no signs of hermaphroditism or change of sex. In cultures of mixed sexes, spawning frequently occurred in numerous dishes on a given day; i.e., cultures on comparable feeding regimes tended to spawn at the same time. Egg masses formed within females are extruded through the mouth (Fig. 1). The eggs are opaque and creamy white, and they vary in diameter from 170 to $240 \mu \mathrm{m}$. The masses consist of a gelatinous-like material which adheres to nearby objects when first extruded. The masses may be small and spherical (up to about 2 or $2.5 \mathrm{~mm}$ diameter) or elongate, and in the extreme, more than $5 \mathrm{~cm}$ long by $3 \mathrm{~mm}$ in diameter (Fig. 2). There may be few eggs, i.e., 5-10, such as reported by Crowell (1946), or there may be many more (the largest egg masses we have seen contained more than 2000 ova). As well as ova, the egg masses contain hundreds, even thousands, of nematosomes. These can be seen rotating in place within the egg mass. In our cultures, sexual reproduction has occurred in every month of the year with no apparent seasonality or correlation with moon phases.

In the first experiment with 16 female and 14 male isolated siblings, we recorded numerous instances when most of both sexes spawned within a few hours of one another, between mid-afternoon and early evening. Females produced from one to three egg masses each spawning, and males released varying amounts of sperm.

In the second experiment, with 12 female and 12 male isolated clonemates, we recorded 322 female and 264 male spawnings; 242 of those by females and 170 of those by males occurred the day after both sexes had eaten mussel and had had their water changed (Table I). Thus $75 \%$ of the female spawnings and $64 \%$ of the male spawnings occurred on the same days and, as before, within a few hours of one another. Of those spawnings, all 12 females spawned in seven cases, and all 12 males spawned in four. On three occasions, all 12 of both sexes spawned on the same day. On the day after eating mussel, at least one female always spawned, but on three occasions, no male spawned.

\section{Embryology and development}

Sperm produced by isolated males can be added to extruded egg masses and development observed. Cleavage leads to translucent blastulae, most of which become invaginate gastrulae $12-15$ hours after fertilization at around $20^{\circ} \mathrm{C}$ (Fig. 3). The gastrulae emerge from the egg mass as 200-250 $\mu \mathrm{m}$ spherical, ciliated planulae $36-48$ hours after fertilization. The planulae alternate between periods of swimming and resting and develop an apical tuft of large cilia that becomes obvious by the third day. They change their shape progressively from spherical, to pear-shaped, to elongate, and by five days, some develop four tentacle buds around the mouth (Figs. 4, 5). At four to five days, there are two thickened areas of tissue internally that represent the first mesenteric couple. By the seventh day, many planulae cease swimming, settle to the bottom, and metamorphose into $250-500 \mu \mathrm{m}$ long juveniles with four tentacles. The metamorphosed young may retain cilia on their columns for more than a month and grow to a length of more than $1 \mathrm{~mm}$ before the cilia are lost. During the first few days after metamorphosis, the juveniles glide over the substrate with the aboral end forward, although they no longer rotate about their longitudinal axes as the planulae did. The direction of movement reverses after a few days, and the juveniles then glide with the oral end leading. Most juveniles cease gliding before they are $1 \mathrm{~mm}$ long.

The young anemones vary considerably in size, and by 10 days some may already be $1 \mathrm{~mm}$ long when fully extended. By two weeks some will have grown to $2 \mathrm{~mm}$ (Fig. 6 ), by three weeks to $4 \mathrm{~mm}$ or slightly longer, and, in the extreme, to $2.5 \mathrm{~cm}$ long in a month. At $2-3$ weeks, a second set of four tentacles develops, and all eight macrocnemes are obvious, although the first couple are much larger than any of the others. This seeming dominance of the first mesenteric couple is a feature that remains obvious for the first several months. Commonly, month-old animals have 12 tentacles, can extend their bodies to $1-$ $2 \mathrm{~cm}$, and possess a few nematosomes. Two-month-old animals are approaching sexual maturity, are $2-5 \mathrm{~cm}$ long, may have 16 tentacles, and have usually developed abundant nematosomes. Some mature sexually and spawn at 

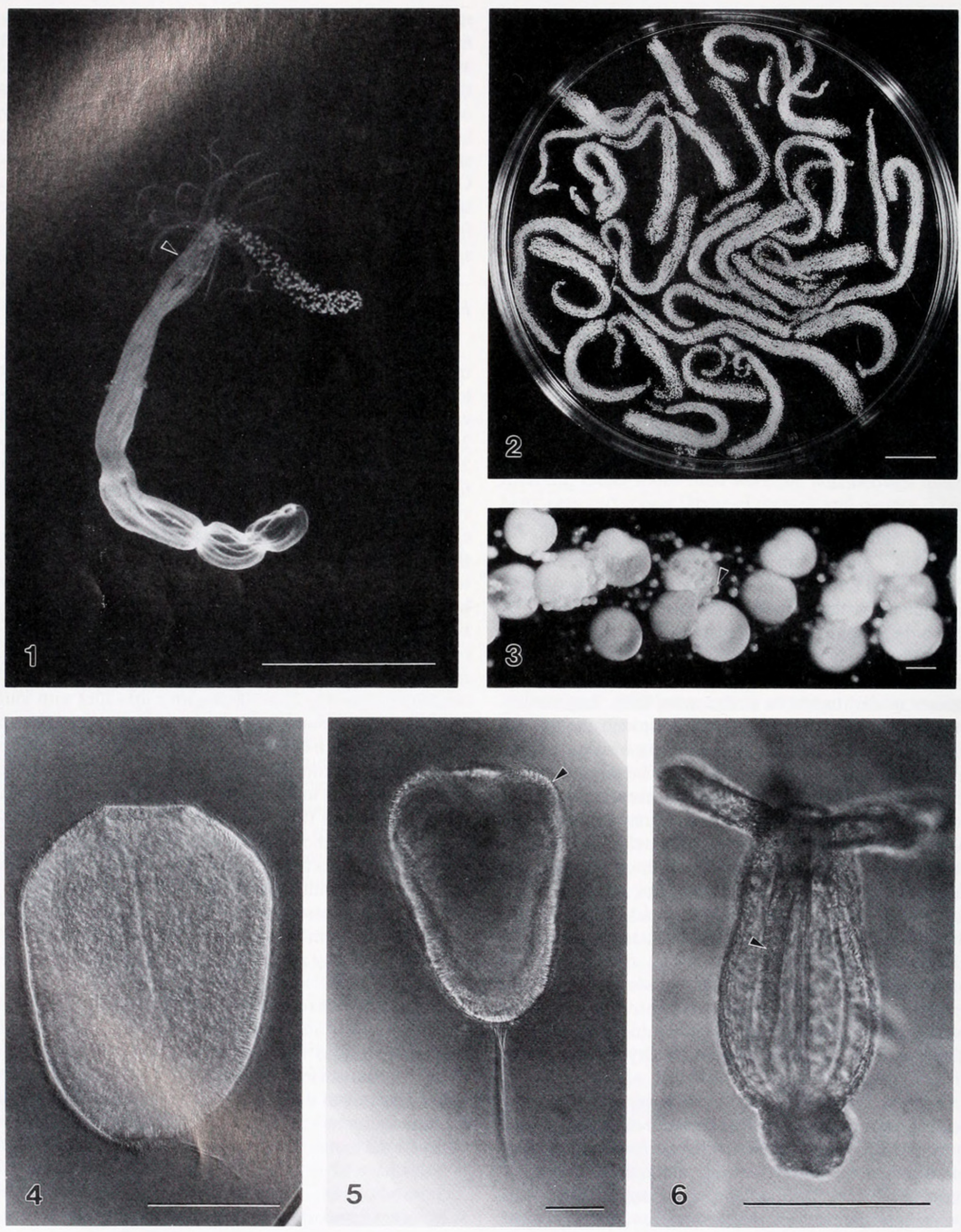
an age of about 10 weeks. Spawning occurred in one culture that was only 69 days post fertilization. Asexual division by transverse fission also becomes common at about 10 weeks. The earliest fission noted was in a seven-weekold individual that was almost $3 \mathrm{~cm}$ long. In about five months, heavily fed animals can grow to expanded lengths exceeding $16 \mathrm{~cm}$, with physal diameters of $4-5 \mathrm{~mm}$, and tentacles $2-3 \mathrm{~cm}$ long.

In every group of developing sea anemones, we have observed variations in timing and size of individuals. Not all planulae metamorphose to juveniles in seven days, and some delay metamorphosis for at least two weeks. In one instance, planulae remained active for as long as 135 days, and in that time their size decreased such that the last one measured, just six days before it was last seen, was about $100 \mu \mathrm{m}$ long. Frequently a few planulae, $1 \%$ or less, remain active for 1-2 months in bowls with their developing siblings, but we do not know whether these are still capable of metamorphosing.

As well as variations in growth rates, we have observed newly metamorphosed juveniles with two and three tentacles rather than the normal four. At ages of several months to a year or more, there may be large variations in the abundance of nematosomes. Too, some individuals have large physal regions or very long tentacles compared to others, and the frequency of asexual reproduction varies greatly from individual to individual. There also may be much variability in planular size, because the planulae in our cultures seldom exceed $500 \mu \mathrm{m}$ long, a size substantially less than those reported by Frank and Bleakney (1976) and Williams (1975).

\section{Nematosomes}

Nematosomes are equally abundant in both sexes. Those embedded in the egg masses emerge from the matrix along with the emerging planulae. They do not move throughout the water column, but tend to remain rotating near the degenerating matrix of the original egg mass. However, both the egg mass matrix and the nematosomes may remain in the dish with the developing anemones for extended periods. We have had nematosomes remain active for as long as 13 days past the date of spawning, and the gelatinous matrix from the egg mass, although shrinking in size, may remain for a month or more.

\section{Other populations}

We have kept cultures from areas other than Chesapeake Bay on feeding and water changing schedules identical to those from Chesapeake Bay. These cultures also tend to spawn synchronously with those from Chesapeake Bay. The development, metamorphosis, and growth of the offspring of those cultures do not differ from those of the Chesapeake Bay anemones.

\section{Salinity}

The anemones in $10 \%$ and $20 \%$ seawater did not do well; we terminated these two cultures at 5 weeks because 18 of the 20 in $10 \%$ seawater, and 13 of the 20 in $20 \%$ seawater, were deflated and had mesenteries everted through their mouths. There had been one asexual division in the group in $20 \%$ seawater. The anemones in the other salinities all produced fertile egg masses and planula larvae, and all planulae, except those in $125 \%$ seawater, metamorphosed to young anemones. At the end of 16 weeks (Table II), we discontinued this study. The anemones in $33 \%$ seawater had grown to be $4-6 \mathrm{~cm}$ long, had spawned four times, and by asexual reproduction had become a group of 29 anemones. The group in $66 \%$ seawater did not grow much, and were barely larger than at the initiation of the experiment. These had spawned four times and had become a group of 28 animals. The anemones in $100 \%$ seawater had decreased in size, the largest being about $2.5 \mathrm{~cm}$ long when fully extended. These anemones had become a group of 26 and had spawned only once. The anemones in $125 \%$ seawater also only spawned once, had become a group of 22 , and decreased in size, the largest being about $2.0 \mathrm{~cm}$ long.

\section{Discussion}

Nematostella vectensis is regarded as a small sea anemone, and Williams (1983) stated that, although they may

Figure 1. Spawning female releasing part of an egg mass. Note the remaining unreleased egg mass in colenteron at the arrow. Scale bar: $1.0 \mathrm{~cm}$.

Figure 2. Egg masses from numerous individuals collected from one evening's spawn. Scale bar: $1.0 \mathrm{~cm}$.

Figure 3. Blastulae, early gastrulae and nematosomes in situ in an egg mass fertilized 14 hours earlier. Arrow points to a nemiatosome. Scale bar: $100 \mu \mathrm{m}$.

Figure 4. Three day post-fertilization planula with early apical tuft. Scale bar: $100 \mu \mathrm{m}$.

Figure 5. Five day post-fertilization planula with fully developed apical tuft and developing tentacle buds. Tentacle bud at arrow. Scale bar: $100 \mu \mathrm{m}$.

Figure 6. Two-week-old, four tentacled juvenile anemone. Arrow points to one member of the first couple of mesenteries. Note its size compared to the adjacent smaller primary mesenteries. Scale bar: $1.0 \mathrm{~mm}$. 
Table I

Spawning of 12 isolated female and 12 isolated male clonemates of Nematostella vectensis from 12 February to 3 October 1990

Females

\begin{tabular}{|c|c|c|c|c|c|c|c|c|c|c|c|c|c|c|}
\hline \multirow[b]{2}{*}{ Day of spawn } & \multicolumn{12}{|c|}{ Number of spawns of anemone } & \multirow{2}{*}{$\begin{array}{c}\text { Total } \\
\text { spawns }\end{array}$} & \multirow[b]{2}{*}{$\%$} \\
\hline & 1 & 2 & 3 & 4 & 5 & 6 & 7 & 8 & 9 & 10 & 11 & 12 & & \\
\hline Day before eating mussel & 3 & 4 & 2 & 3 & 1 & 2 & 4 & 2 & 3 & 3 & .1 & 4 & 32 & 10 \\
\hline Day of eating mussel & 1 & 0 & 0 & 0 & 1 & 0 & 0 & 0 & 0 & 0 & 1 & 1 & 4 & 1 \\
\hline Day after eating mussel & 20 & 18 & 20 & 21 & 21 & 22 & 19 & 21 & 21 & 19 & 19 & 21 & 242 & 75 \\
\hline Other days & 3 & 3 & 5 & 4 & 3 & 5 & 3 & 2 & 7 & 3 & 2 & 4 & 44 & 14 \\
\hline Sum & 27 & 25 & 27 & 28 & 26 & 29 & 26 & 25 & 31 & 25 & 23 & 30 & 322 & 100 \\
\hline
\end{tabular}

\begin{tabular}{|c|c|c|c|c|c|c|c|c|c|c|c|c|c|c|}
\hline \multirow[b]{2}{*}{ Day of spawn } & \multicolumn{12}{|c|}{ Number of spawns of anemone } & \multirow{2}{*}{$\begin{array}{c}\text { Total } \\
\text { spawns }\end{array}$} & \multirow[b]{2}{*}{$\%$} \\
\hline & 1 & 2 & 3 & 4 & 5 & 6 & 7 & 8 & 9 & 10 & 11 & 12 & & \\
\hline Day before eating mussel & 0 & 0 & 1 & 0 & 0 & 0 & 0 & 1 & 0 & 0 & 0 & 0 & 2 & 1 \\
\hline Day of eating mussel & 6 & 2 & 6 & 6 & 4 & 5 & 6 & 3 & 7 & 5 & 8 & 3 & 61 & 23 \\
\hline Day after eating mussel & 16 & 13 & 15 & 12 & 16 & 15 & 11 & 13 & 11 & 17 & 16 & 15 & 170 & 64 \\
\hline Other days & 1 & 5 & 2 & 1 & 0 & 2 & 2 & 6 & 5 & 1 & 4 & 2 & 31 & 12 \\
\hline Sum & 23 & 20 & 24 & 19 & 20 & 22 & 19 & 23 & 23 & 23 & 28 & 20 & 264 & 100 \\
\hline
\end{tabular}

All anemones were fed brine shrimp nauplii every second day. Each eighth day they were fed pieces of Mytilus californianus ovary and the water was changed. All were mature, $6-10 \mathrm{~cm}$ long adults at the initiation of the test and were maintained in $33 \%$ seawater.

be up to $6 \mathrm{~cm}$ long, they are usually less than $2 \mathrm{~cm}$. We were surprised, therefore, when our laboratory specimens grew to more than twice the maximum size reported previously. All earlier size measurements appear to have been made on recently collected animals, and not well-fed cultured ones. The small size of the sea anemones in the field, relative to the larger sizes in our cultures, must reflect the small amount of food they capture in their native habitats.

The production of gelatinous egg masses by Nematostella is a unique feature of this sea anemone, although the eggs of Halcampa duodecimcirrata, which are released individually, become surrounded by a jelly envelope after fertilization (Nyholm, 1949). The jelly attaches the eggs to the sandy bottom in which Halcampa lives.
We know of no other sea anemone that spawns repeatedly over extended periods, although an annual period of reproductive activity is known for many sea anemones (Jennison, 1979). N. vectensis may well have an annual reproductive cycle in nature; but in the laboratory it has spawned repeatedly and on a predictable schedule. We have tried feeding mussel tissue every fourth day to some female clonemates of the anemones on the eight-day cycle. The results led to spawns in an erratic and unpredictable fashion; apparently $N$. vectensis cannot spawn repeatedly at four-day intervals. We now are attempting a seven-day cycle, and early results suggest that predictable spawnings will occur at seven-day intervals.

How the reproductive cycle of $N$. vectensis operates in nature is unknown. Most populations of this anemone

Table II

Asexual reproduction, growth, and spawning during 16 weeks in various concentrations of seawater

\begin{tabular}{|c|c|c|c|c|c|}
\hline $\begin{array}{c}\text { Sea water } \\
\text { concentration }\end{array}$ & $\begin{array}{c}\text { Initial } \\
\text { number }\end{array}$ & $\begin{array}{c}\text { Final } \\
\text { number }\end{array}$ & $\begin{array}{l}\text { Largest } \\
\text { final size }\end{array}$ & $\begin{array}{l}\text { Number of } \\
\text { spawns }\end{array}$ & $\begin{array}{c}\text { Larvae } \\
\text { metamorphosed }\end{array}$ \\
\hline $33 \%$ & 20 & 29 & $6.0 \mathrm{~cm}$ & 4 & yes \\
\hline $66 \%$ & 20 & 28 & $3.5 \mathrm{~cm}$ & 4 & yes \\
\hline $100 \%$ & 20 & 26 & $2.5 \mathrm{~cm}$ & 1 & yes \\
\hline $125 \%$ & 20 & 22 & $2.0 \mathrm{~cm}$ & 1 & no \\
\hline
\end{tabular}

All anemones were $2.0-3.0 \mathrm{~cm}$ long, six-month-old siblings at the initiation of the experiment. All were fed brine shrimp nauplii every second day, and the water was changed every one to two weeks. 
live in pools in marshes at tidal elevations that do not necessarily receive fresh water with each tidal cycle, and their food consists of denizens of the pools they inhabit (Lindsay, 1975; Williams, 1976; Frank and Bleakney, 1978). The higher tides generally provide fresh seawater to the pools, and at times that water must carry large amounts of plankton. We wonder whether the pulses of extra food, in the form of the mussel ovary that we supply, may mimic pulses of extra food from the plankton that they receive in nature. Perhaps that pulse of food, along with the change of water, is the key to the release of gametes in $N$. vectensis.

The planula larvae of $N$. vectensis, from the age of about three days onward, are active swimmers, although they do spend long periods immobile on the bottoms of our culture dishes. Some swimming is spontaneous, but if the cultures are disturbed, most of the motionless planulae leave the bottom and swim actively. They swim in a clockwise spiral, as viewed from the oral end of the planula, and while doing this they rotate around their longitudinal axes in a clockwise direction. Widersten (1968) reported similar rotation in several cnidarian larvae, including several species of sea anemones, although he also observed some anemone planulae that rotated either clockwise or counterclockwise. In contrast to the generally clockwise rotation of the sea anemone larvae, he found only counterclockwise rotation in hydrozoan and scyphozoan planulae.

The reversal in the direction of gliding by the juvenile anemones was unexpected and is previously unreported. We presume that the same cilia that move the planulae in an aboral direction later reverse their beat and move the recently metamorphosed anemones in an oral direction. But the juveniles could alternatively be propelled by newly developed cilia.

In the only specific study of nematosomes, Williams (1979) found no correlation between the size of an anemone and the number of its nematosomes, and we agree. $\mathrm{He}$ also considered nematosomes to be functionless, and although we find that difficult to accept, their function is certainly not obvious. In his study, Williams also showed that nematosomes removed from anemones had relatively short lives; i.e., only those maintained at low temperature $\left(1.5-3.5^{\circ} \mathrm{C}\right)$ lived as long as 55 hours. In sharp contrast, we found that nematosomes would live for 13 days outside of the body of anemones at temperatures around $20^{\circ} \mathrm{C}$. Williams (1979) made his observations on material in normal seawater $(34 \%)$, whereas our material was in a salinity of about $12 \%$. Too, we did not artificially free the nematosomes from the anemones. Our observations were on nematosomes contained in egg masses, from which they emerged along with the planulae.

As we noted earlier, $N$. vectensis is a euryhaline sea anemone; it can be found in widely varying salinities. Our own experience in culturing this anemone confirms that we are dealing with a widely tolerant euryhaline, eurythermal sea anemone, and we know of no other sea anemone of equal tolerance. Not only is $N$. vectensis tolerant, but it carries out its full repertoire of sexual and asexual reproduction, development, and growth in a wide range of salinities. When cultured in full strength seawater, or higher salinities, growth seems to be inhibited, and we have not observed successful sexual reproduction and subsequent metamorphoses in salinities greater than $34 \%$.

Sexual reproduction and the subsequent development in sea anemones have rarely been studied (see review by Stephenson, 1928; also Mergner, 1971; Campbell, 1974; and Fautin et al., 1989). Those species that have been reported upon had all been recently collected, brought in to a nearby laboratory or field station, and subsequently spawned. Fortuitously, investigators on the scene, such as Nyholm (1943, 1949), Chia and Spaulding (1972), Siebert (1973, 1974), Riggs (1988), and Chia et al. (1989), have been able to examine some of the events from spawning onwards, although until now there have been no reports of rearing of successive generations of any species. Most studies do not describe development beyond the planula, although those of Spaulding (1972) on Peachia quinquecapitata, Chia and Spaulding (1972) on Tealia crassicornis, and Siebert (1973) on Stomphia didemon are exceptions. Of all the studies of development of sea anemones, we are aware of only two (Clark and Dewell, 1974; Larkman and Carter, 1984) that have provided a close look at fertilization and related events. Those studies, like the others we have cited on matters related to development, were largely made possible by spontaneous spawnings and not as the result of planned or controlled spawnings. Now that we can culture Nematostella throughout its life history and can control some of the variation through the use of clonal anemones, we can look closely and repeatedly at all events, from fertilization to spawning. Moreover, the short generation time of two to three months in laboratory-reared Nematostella will allow ready genetic analyses. Because Nematostella can be cultured away from marine facilities, research on every aspect of its life history can be carried out at inland laboratories, and we believe this sea anemone has the potential to become an important model for research in cnidarian biology.

\section{Acknowledgments}

We are grateful to Martin Posey for the material from Chesapeake Bay, and we also owe our thanks to the following for other material: Martin Sheader and Daphne Fautin for specimens from England; Sherman Bleakney for specimens from Nova Scotia; R. T. Kneib for specimens from Georgia; Edward Lyke, Daniel Wickham, and 
Pamela Roe for specimens from California; Jon Geller for specimens from Oregon; Eugene Kozloff, Edward Lyke, and Claudia Mills for specimens from Washington. We thank Tzyy-ing Chen, Jennifer Russo, and Eleanor Uhlinger for their help in caring for our animals, and we are grateful for the assistance Beth Clark provided in the preparation of our manuscript. Fred Griffin and Eduardo Almeida each provided invaluable assistance with photography and we thank Wallis Clark for the use of his laboratory's photographic and optical equipment. Comments and suggestions from Wallis Clark, Fred Griffin, and Eleanor Uhlinger have been of great assistance in the development of the manuscript. This work is a result of research sponsored in part by NOAA, National Sea Grant College Program, Department of Commerce, under grant number NA89AA-D-SG138, project number 83-A-N, through the California Sea Grant College. The U.S. Government is authorized to reproduce and distribute reprints for governmental purposes.

\section{Literature Cited}

Bleakney, J. S., and K. B. Meyer. 1979. Observations on saltmarsh pools, Minas Basin, Nova Scotia 1965-1977. Proc. N.S. Inst. Sci. 29: 353-371.

Calder, D. 1972. Phylum Cnidaria. Pp. 97-107 in A Check List of the Biota of Lower Chesapeake Bay. Special Scientific Report No. 65, Virginia Institute of Marine Science.

Campbell, R. D. 1974. Cnidaria. Pp. 133-199 in Reproduction of Marine Invertebrates, Vol. 1, Acoelomate and Pseudocoelomate Metazoans, A. C. Giese and J. S. Pearse, eds. Academic Press, New York.

Cary, L. R. 1911. A study of pedal laceration in actinians. Biol. Bull. 20: $81-108$.

Chia, F.-S., and J. G. Spaulding. 1972. Development and juvenile growth of the sea anemone Tealia crassicornis. Biol. Bull. 142: 206218.

Chia, F.-S., J. Lützen, and I. Svane. 1989. Sexual reproduction and larval morphology of the primitive anthozoan Gonactinia prolifera M. Sars. J. Exp. Mar. Biol. Ecol. 127: 13-24.

Clark, W. H., Jr., and W. C. Dewel. 1974. The structure of the gonads, gametogenesis, and sperm-egg interactions in the Anthozoa. Am. Zool. 14: $495-510$.

Clayton, W. S., Jr., and H. R. Lasker. 1984. Host feeding regime and zooxanthellal photosynthesis in the anemone, Aiptasia pallida (Verrill). Biol. Bull. 167: 590-600.

Crowell, S. 1946. A new sea anemone from Woods Hole, Massachusetts. J. Wash. Acad. Sci. 36: 57-60.

Fautin, D. G., J. G. Spaulding, and F.-S. Chia. 1989. Cnidaria. Pp. 43-62 in Reproductive Biology of Invertebrates, Vol. IV. Part A. K. A. Adiyodi and R. G. Adiyodi, eds. John Wiley \& Sons, Chichester.

Frank, P., and J. S. Bleakney. 1976. Histology and sexual reproduction of the anemone Nematostella vectensis Stephenson 1935. J. Nat. Hist. 10: $441-449$.

Frank, P., and J. S. Bleakney. 1978. Asexual reproduction, diet and anomolies of the anemone Nematostella vectensis in Nova Scotia. Can. Field-Nat. 92: 259-263.

Hand, C. 1957. Another sea anemone from California and the types of certain California species. J. Wash. Acad. Sci. 47: 411-414.

Heard, R. W. 1982. Guide to common tidal marsh invertebrates of the northern Gulf of Mexico. Mississippi Alabama Sea Grant Consortium. Publ. 79-004, 82 pp.
Jennison, B. L. 1979. Gametogenesis and reproduction cycles in the sea anemone Anthopleura elegantissima (Brandt, 1835). Can. J. Zool. 57: 403-411.

Jensen, L. D. 1974. Environmental responses to thermal discharges from the Indian River Station, Indian River, Delaware. Electric Power Research Institute. Report No. 12. Publ. No. 74-049-00-3.

Kneib, R. T. 1985. Predation and disturbance by grass shrimp, Palaemonetes pugio Holthuis, in soft-substratum benthic invertebrate assemblages. J. Exp. Mar. Biol. Ecol. 93: 91-102.

Larkman, A. U., and M. A. Carter. 1984. The apparent absence of a cortical reaction after fertilization in a sea anemone. Tissue \& Cell 16: $125-130$.

Lindsay, J. A. 1975. A salt marsh anemone. Mar. Aquarist 6(8): 43-48.

Mergner, H. 1971. Cnidaria. Pp. 1-84 in Experimental Embryology of Marine and Freshwater Invertebrates, G. Reverberi, ed. North Holland Press, Amsterdam.

Minasian, L. L., Jr., and R. N. Mariscal 1979. Characteristics and regulation of fission activity in clonal cultures of the cosmopolitan sea anemone, Haliplanella luciae (Verrill). Biol. Bull. 157: 478-493.

Muller-Parker, G. 1984. Photosynthetic-irradiance responses and photosynthetic periodicity in the sea anemone Aiptasia pulchella and its zooxanthellae. Mar. Biol. 82: 225-232.

Nyholm, K. G. 1943. Zur Entwicklung und Entwicklungsbiologie der Ceriantharien und Aktinien. Zool. Bidr. Uppsala 22: 87-248.

Nyholm, K. G. 1949. On the development and dispersal of Athenaria actinia with special reference to Halcampa duodecimcirrata M. Sars. Zool. Bidr. Uppsala 27: 465-506.

Riggs, L. L. 1988. Feeding behavior in Aiptasia tagetes (Duchassaing and Michelotti) planulae: a plausible mechanism for zooxanthellae infection of aposymbiotic planktotrophic planulae. Caribb. J. Sci 24: 201-206.

Rudy, P., Jr., and L. H. Rudy. 1983. Oregon Estuarine Invertebrates. An Illustrated Guide to the Common and Important Invertebrate Animals. Fish and Wildlife Service. FWS/OBS-83/16.

Siebert, A. E., Jr. 1973. A description of the sea anemone Stomphia didemon sp. nov. and its development. Pac. Sci. 27: 363-376.

Siebert, A. E., Jr. 1974. A description of the embryology, larval development, and feeding of the sea anemones Anthopleura elegantissima and A. xanthogrammica. Can. J. Zool. 52: 1383-1388.

Spaulding, J. G. 1972. The life cycle of Peachia quinquecapitata, an anemone parasitic on medusae during its larval development. Biol. Bull. 143: 440-453.

Stephenson, T. A. 1928. The British Sea Anemones, Vol. I. The Ray Society, London.

Stephenson, T. A. 1929. On methods of reproduction as specific characters. J. Mar. Biol. Assoc. U.K. 16: 131-172.

Stephenson, T. A. 1935. The British Sea Anemones, Vol. II. The Ray Society, London.

Widersten, B. 1968. On the morphology and development in some cnidarian larvae. Zool. Bidr. Uppsala 37: 139-182.

Williams, R. B. 1975. A redescription of the brackish-water sea anemone Nematostella vectensis Stephenson, with an appraisal of congeneric species. J. Nat. Hist. 9: 51-64.

Williams, R. B. 1976. Conservation of the sea anemone Nematostella vectensis in Norfolk, England and its world distribution. Trans. Norfolk Norwich Nat. Soc. 23: 257-266.

Williams, R. B. 1979. Studies on the nematosomes of Nematostella vectensis Stephenson (Coelenterata, Actiniaria). J. Nat. Hist. 13:6980.

Williams, R. B. 1983. Starlet sea anemone: Nematostella vectensis. Pp. 43-46 in The IUCN Invertebrate Red Data Book. IUCN, Gland, Switzerland. 


\section{$2 \mathrm{BHL}$ Biodiversity Heritage Library}

Hand, Cadet and Uhlinger, Kevin R. 1992. "The Culture, Sexual and Asexual Reproduction, and Growth of the Sea Anemone Nematostella vectensis." The Biological bulletin 182, 169-176. https://doi.org/10.2307/1542110.

View This Item Online: https://www.biodiversitylibrary.org/item/17417

DOI: https://doi.org/10.2307/1542110

Permalink: https://www.biodiversitylibrary.org/partpdf/8125

\section{Holding Institution}

MBLWHOI Library

\section{Sponsored by}

MBLWHOI Library

\section{Copyright \& Reuse}

Copyright Status: In copyright. Digitized with the permission of the rights holder.

License: http://creativecommons.org/licenses/by-nc-sa/3.0/

Rights: https://biodiversitylibrary.org/permissions

This document was created from content at the Biodiversity Heritage Library, the world's largest open access digital library for biodiversity literature and archives. Visit BHL at https://www.biodiversitylibrary.org. 